\title{
Perspective in Stage Design: An Application of Principles of Anamorphosis in Spatial Visualisation
}

\author{
Aleksandar Ččaković ${ }^{1}$ - Marijana Paunović P̌ $^{2}$
}

Published online: 5 April 2016

(C) Kim Williams Books, Turin 2016

\begin{abstract}
The goal of this paper is to demonstrate the various models of perspective anamorphosis used in the visual arts, which are also applicable to stage design. Through comparative analysis, borderline conditions emerge through which certain perspective models assume traits of anamorphosis, as well as conditions for their use in stage design. The idea is to provide practical instructions which are usable on the stage. This effort saw the use of constructive perspective methods, projective and descriptive geometry, while retaining a pictorial and an opticalphysiological perspective. The examples of stage design that are shown in the paper are mostly from the National Theatre in Belgrade, the oldest theatre in Belgrade, and an institution that collaborates with the Faculty of Applied Arts. The perspective models of anamorphosis, analysed here, were chosen according to the unique features of the stage and its elements, which include: a perspective image projected on multiple planes, relief perspective as the anamorphosis of space, and the cylindrical perspective.
\end{abstract}

Keywords Descriptive geometry - Stage design - Relief perspective * Cylindrical perspective - Representations of architecture - Virtual architecture - CAD - Viewing angle - Constructive perspective ·

Pictorial perspective

Marijana Paunović

marijanavpaunovic@gmail.com

Aleksandar Čučaković

cucak@grf.bg.ac.rs

1 Department of Mathematics, Physics and Descriptive Geometry, Faculty of Civil Engineering, University of Belgrade, Bulevar kralja Aleksandra 73/I, 11000 Belgrade, Serbia

2 Department of Applied Graphics, Faculty of Applied Arts, University of Arts in Belgrade, Kosančićev venac 29, 11000 Belgrade, Serbia 


\section{Introduction}

Perspective anamorphosis is a type of optical anamorphosis, made according to the principles of constructive perspective and observed from the viewpoint from which it's constructed. In a wider sense, as with other types of anamorphoses, it is a form to which specific projections give more meaning (Čučaković and Paunović 2015, p. 605). Having in mind how important the method of performing scenography is in stage design, its simplicity, its optimal viewing by the audience, and its utilisation by the actors, the purpose of this research is to identify the potentials of certain spatial models of perspective anamorphosis in stage design and to provide a set of recommendations for their realisation. The paper was intended to emphasise the technical possibilities of anamorphosis, without prejudice to its historically determined mythological and magical meanings, and their context.

Looking at the greatest examples, such as Palladio's Teatro Olimpico in Vicenza, Borromini's colonnade in the Pallazzo Spada, and Bramante's Santa Maria presso San Satiro in Milan-which are the subjects of relief perspective of applied geometry classes at the Faculty of Applied Arts in Belgrade-we decided to show and analyse examples from our locality. The reason the analyses of perspective anamorphosis were performed using the example of the stage of The National Theatre in Belgrade was based on the fact that the Faculty of Applied Arts and this theatre have a tradition of many years of collaboration.

Students from the departments of stage costume and scenography of the aforementioned faculty have the benefit of being able to acquaint themselves better with relevant practical work through the relationship with this theatre. The National Theatre in Belgrade was built in the Principality of Serbia in 1869 by architect Aleksandar Bugarski, as a symbol of the country's liberation. Historians compare the façade of the theatre with La Scala in Milan, but additionally emphasise the interior finishes (with applied motifs of the Renaissance, Baroque and Rococo style), which are significantly more luxurious than the reduced exterior (Kadijević 2005, p. 301).

It was within a short space of time that the theatre first underwent reconstruction, and one of the biggest of these was within 40 years of initial construction, and was carried out by architect Josif Bukavac. The most recent reconstruction was in 1986-performed by the main architects Ljubomir Zdravković and Slobodan Drinjaković, when the stage was modernised. The interior was realised according to the projects of Milan Pališaški. Currently the theatre has a Main Stage with 559 seats and the "Raša Plaović" stage with 285 seats.

On the Main Stage of the National Theatre in Belgrade (Fig. 1), there are noticeable potentials for implementing perspective anamorphosis. The centre stage (which encompasses the floor surface and the airspace behind the proscenium arch, and is intended for performing stage programs), and upstage (the space behind the centre stage, which is less wide or as wide the centre stage, and is used as a reserve space in situations where a theatre performance with greater depth is required), and on which it is impossible to implement monumental perspective decor (Fig. 1a), are framed by cycloramas (large-dimension semi-circular pieces 


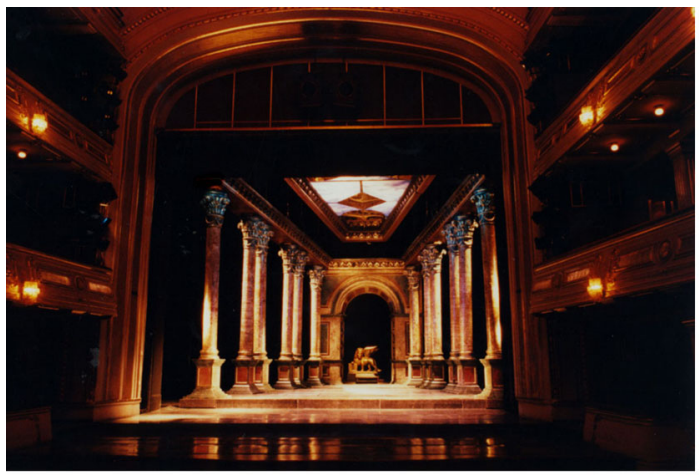

(a)

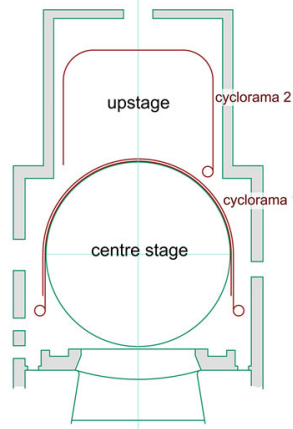

(b)

Fig. 1 National theatre in Belgrade, Serbia; a Maksim Crnojević, scenography of Geroslav Zarić, 2007 (source Geroslav Zarić); b Schematic representation of the Main Stage base (image: author)

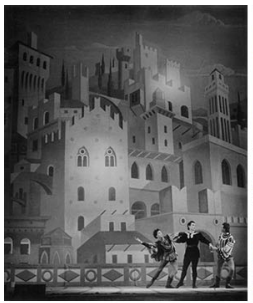

(a)

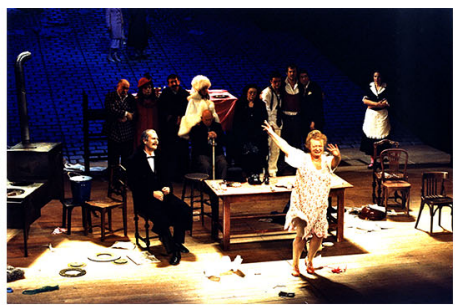

(b)

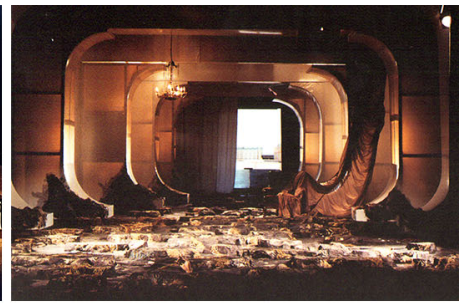

(c)

Fig. 2 Achieving the effect of spatial depth: a Romeo and Juliet, scenography by Dušan Ristić, 1965, National Theatre in Belgrade, Serbia, from the archives of The Museum of Theatre Art of Serbia, Belgrade; b Gospodja Ministarka, scenography by Boris Maksimović, 2004, National Theatre in Belgrade, Serbia, from the archives of The Museum of Theatre Art of Serbia, Belgrade; c Saint George Slays the Dragon, scenography by Miodrag Tabački, 1987, Joakim Vujić Theatre, Kragujevac, (source Miodrag Tabački)

of canvas that are horizontally movable via electro-motors). The first cyclorama has the form of a rotational semi-cylinder and is used as the backdrop of the centre stage, while the second one is parallel to the upstage walls, given its rounded corners (Fig. 1b).

The most frequent use of constructive perspective models on the centre stage takes place when solving the moving horizon background, a curtain which limits the performance area (Fig. 2a), or when achieving a greater horizontal plane depth by placing a slanted trapezoidal ramp, which is a principle of relief perspective (Fig. 2b). The movable backdrop composition, which can be a presentation of architecture, landscape or an open space with architectural elements, is usually achieved using aerial and colour perspective. ${ }^{1}$ Aside from the aforementioned, a

\footnotetext{
1 In his study Trattato della Pittura, Leonardo Da Vinci devoted special chapters to aerial perspective (Da Vinči 1990, p. 95), as well as colour perspective (Da Vinči 1990, p. 77).
} 
parallel plane anamorphosis model is often used to achieve greater spatial depth (Fig. 2c) where the effect depends on pictorial principles. This anamorphosis has an imaginary painting (the initial sketch), which is diffused into parallel planes and is visible from all angles, given that the centre of the projection is in infinity. From a technical perspective, the planes are often emphasised with stage curtains and soffits arranged tonally by depth, sometimes in such a way as to expand the deeper they go, thereby closing the field of view and emphasising the perspective through an empty performance space, which assumes the form of a truncated pyramid.

An important task of a scenographer is to enable the optimal visibility of the stage elements from all angles, or to make certain points of view satisfying and acceptable. Therefore, the examples of certain models of perspective anamorphosis, which are applicable in stage design, are displayed.

\section{Perspective Image Projected on Multiple Planes}

Perspective anamorphoses projected on multiple planes are spatial models where the object image is obtained when vision rays pass through multiple planes, all originating from a certain viewpoint. Depending on the position of the object towards the aforementioned projection planes, the perspective on some planes can contain one, two or three vanishing points.

This means that the image on some planes is positioned according to the conventional principles of perspective projection with acceptable deformations (visual angle ${ }^{2}$ is optimally between $60^{\circ}$ and $90^{\circ}$ ), while on others the image has pronounced deformations due to the increased visual angle. In order for the perspective image to have the traits of anamorphosis, it has to fulfil the conditions of unrecognisability, which means that it is recognisable only when it is viewed from a certain viewpoint or a viewpoint field. When talking about scenography, the audience most frequently notices just the effect of the perspective or anamorphosis (unless it is a part of the scenery) without being able to understand its nature, due to their inability of being able to notice the distortion effect. However, the question of whether the perspective projection is an anamorphosis, or not, is important to a stage designer, as the anamorphosis significantly disrupts the control and verification of potential constructive and artistic mistakes. By gaining experience in creating such stage designs, the designer becomes accustomed to viewing distortions both from different orthogonal projections and other view angles. "The scientific solution of representation derives from the reduction of three-dimensional forms to the plane by means of projective and descriptive geometry, but in actual fact architects resorted to plane sections for the study of three-dimensional objects, even before these were codified" (Rossi 2006, p. 112).

\footnotetext{
2 The visual angle is different from the viewing angle and is defined as an angle in a certain plane, most often the horizontal or vertical one, where the main visual ray is perpendicular to the drawing plane or a curved surface's tangential plane. The viewing angle has the viewpoint as the vertex, and the rays are in the tangential planes of the object. This is explained in the optical-physiological perspective, in which the process of optical perception is successive, temporal phenomena.
} 
Image unrecognisability in a multi-plane perspective is achieved by using two factors: the visual representation division and the size of the visual angle. The more planes the image is projected onto, the more pronounced the unrecognisability.

Furthermore, all objects that do not enter the field of vision under an angle of $90^{\circ}$ will be distinctly distorted. Parallel directional lines that enter the drawing plane under a $45^{\circ}$ angle form a visual angle of $90^{\circ}$, which means that all perspective projections that enter the field outside the distance circle are distorted. Thus, if we seek to solve every image projection plane as a separate drawing plane, then the image on some of these planes needs to be outside of the distance circle (Fig. 3a). Two distance circles are emphasised on the illustration, one $d v$ for the vertical and the other $d h$ for the horizontal drawing plane.

Depending on how the imaginary object (or image) is placed in relation to the drawing plane, we can differentiate a combination of perspective projections and thereby form groups of these models.

\section{Frontal Perspective}

Varini's (Felice Varini) anamorphosis (Fig. 3b) has an imaginary image, which lies in a plane parallel to one of the walls of a square-shaped room, which means that this image can be solved on all walls by using a frontal perspective. On the aforementioned frontal wall and on the parallel walls, the perspective image enlarges with distance, without deformations. On the walls that are orthogonal to the imaginary image plane, the projection is outside of the distance circle, which creates the distortion and unrecognisability effects (except when perceived from the point it originates from).

This anamorphosis has the effect of an imaginary plane in which a rectangular geometric image is projected. The effect of a shaded rectangle, instead of a freeform irregular figure, is achieved through the following basic law of visual observation: "Every configuration strives to be seen in such a way for the resulting structure to be as simple as the conditions will allow" (Arnhajm 1981, p. 52). Arnheim's conclusion, which he arrived at through experiments involving observations through

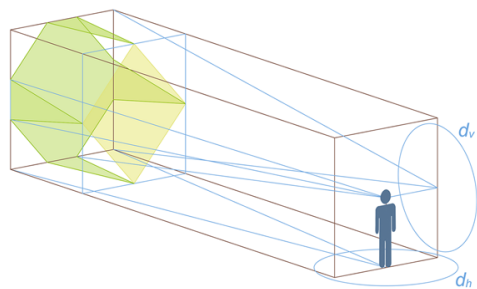

(a)

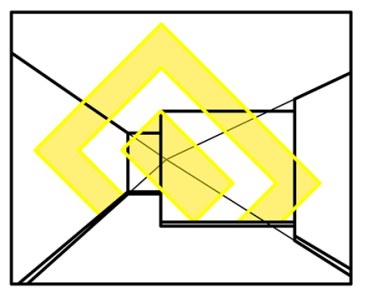

(b)

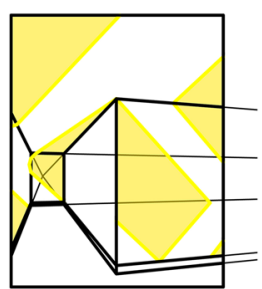

Fig. 3 Perspective anamorphosis with 2D effect projected on multiple planes (image: author); a Perspective geometry of spatial anamorphosis when the imagined image is projected on five mutually orthogonal planes, axonometric projection; b schematic display of the anamorphosis Rettangoli gialli concentrici senza angoli al suolo, Felice Varini, Lugano, Switzerland, 1997 
a hole in a glowing trapezoid on a floor of a rectangular dark room, goes like this: "The observation will correspond to the shape of the physical object when, and only when, that shape represents the simplest image whose projected composition can be seen as a deformation" (Arnhajm 1981, p. 231). By this we can conclude that the imaginary image plane is parallel with the frontal walls. However, what is more pronounced is the vagueness of the distance between the imaginary image plane and the observer, as the frontal perspective enables multiple readings of the frontally positioned image. To be able to view the image as a square (Fig. 4a) in a certain plane (f1, f2 or f3), it has to be positioned into a suitable relationship to real space. This is achieved through visual elements and principles, such as: repetition, composition, size, colour, shading, and hue, which are most frequently used in combination with the constructive perspective. Such examples are Salle des Perspectives, Villa Farnesina by Baldassare Peruzzi (Fig. 4b) and the Hoogstraten perspective (Samuel van Hoogstraten) box (Fig. 4c), where the repetition of the floor motif through the constructive perspective is resolved on the vertical plane.

Unlike Peruzzi's hall, Hoogstraten's box perspective has an orthogonal trihedron, or two vertical planes on which the floor ornament penetration is resolved by using a frontal perspective. Aside from the effect of an expanded space and the penetration of the picture plane, an effect where imaginary objects are located in real space (two chairs and a dog), is created. On the computer model (Fig. 5a) we can see two red chairs in the corners of the box.

Apart from this, it has two viewpoints from which images are constructed so as to create the impression of a single enlarged space. Despite the fact that the three internal box panels (ceiling, frontal wall and floor) are visible from both viewpoints, the fields of vision do not overlap, meaning they encompass different parts of the aforementioned panel. Perspective images, which are viewed from both viewpoints, undermine the spatial relations of the box by creating the illusion of a larger internal space. The ceiling anamorphosis, visible through the left peephole (Fig. 5b), creates an impression for the viewer of a ribbed ceiling on a higher elevation than the actual box.

The distance circles are pronouncedly smaller in the perspective images on the box's frontal surface ( $d \mathrm{fl}, d \mathrm{fr})$, ceiling ( $d \mathrm{lb}$ ) and floor $(d \mathrm{tr})$, than those on the left $(d \mathrm{lr})$ and right $(d \mathrm{rl})$ surface. Images are projected on the frontal panel, ceiling and

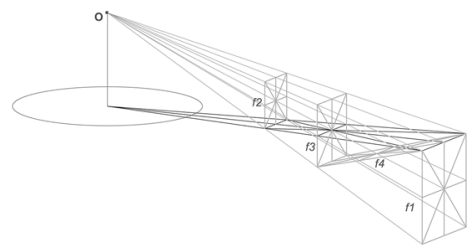

(a)

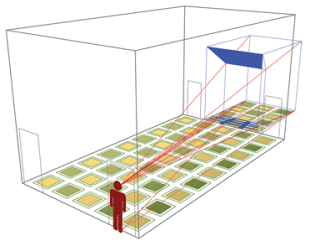

(b)

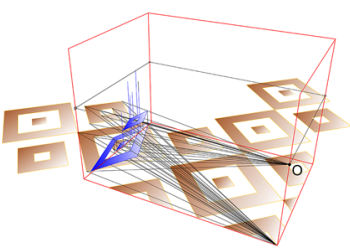

(c)

Fig. 4 Frontal perspective anamorphosis and the position of the imaginary object, perspective depictions: a where the position of an imagined picture of a square (e.g. vertical plane f1, f2 or f3) is indeterminate, perspective projection (Paunović 2014, p. 261); b where the position of a imagined space is determined, perspective analysis Peruzzi's Hall, (Cucakovic and Paunovic 2011, p. 206); c where the position of an imagined space is determined, perspective analysis of Hoogstraten's box (Cucakovic and Paunovic 2011, p. 206) 


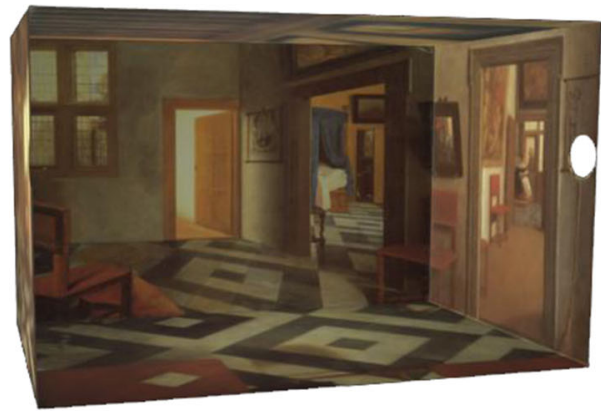

(a)

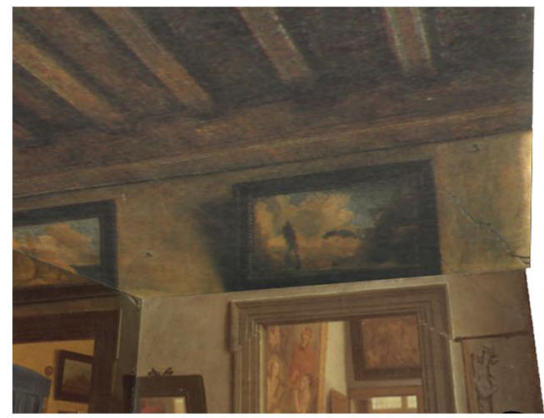

(b)

Fig. 5 Computer 3D model of Samuel van Hoogstraten's box perspective, London, 1655-1660, The National Gallery, solved based on the panel reproduction (image: author); a view through an opening; b view from a left peephole

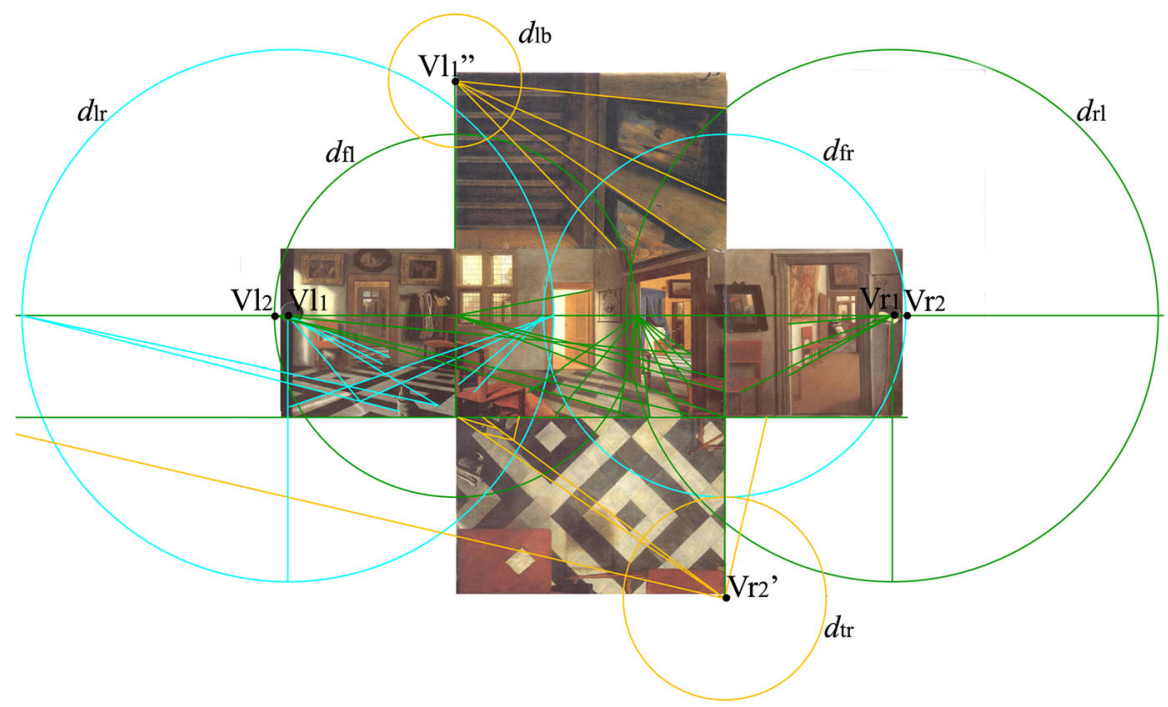

Fig. 6 Restitution of distance circles conducted upon the unfolding of Hoogstraten's box (Cucakovic and Paunovic 2011, p. 207)

floor through both peepholes located outside of the distance circle (Fig. 6), thereby creating deformation.

\section{Angular Perspective}

With multi-plane, angular perspective anamorphosis models, the orthogonal coordinate system is placed under a certain angle in relation to one or several drawing planes. An example of this is the perspective box with the motif of the 


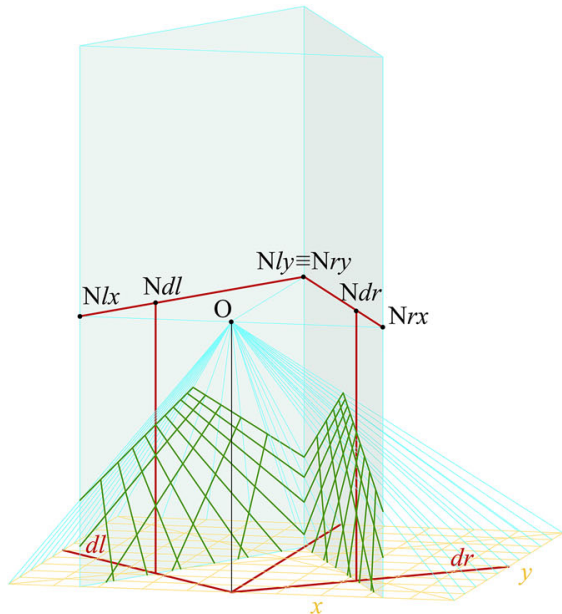

(a)

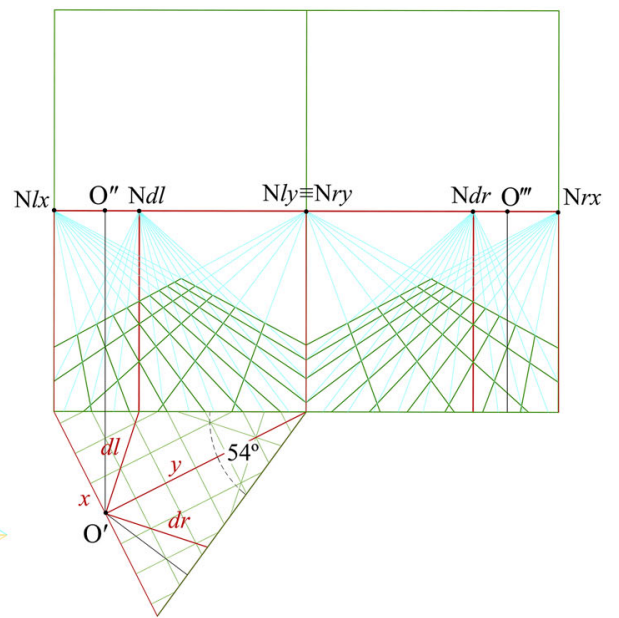

(b)

Fig. 7 Analysis of the vanishing points, box with the Protestant church motif, National Museum, Copenhagen, 1655-1660 (image: author); a axonometric display; b perspective box disassembly

Copenhagen Protestant church (Fig. 7). It has the shape of a straight prism, the base of which is an isosceles triangle $\left(54^{\circ}, 63^{\circ}\right)$, so that the drawing planes comprise a $54^{\circ}$ angle (Verweij 2010, p. 59), and each one individually, from the plane, which has the peephole, has a $63^{\circ}$ angle. The space is resolved through an angular perspective as a Cartesian coordinate system is defined in relation to the dominant horizontal grid.

The vanishing points on the left Nlx, Nly and the right Nrx, Nry of the horizontal $\mathrm{x}$ and $\mathrm{y}$ direction box, as well as the vanishing points of the horizontal diagonals (under a $45^{\circ}$ angle) $\mathrm{N} d l$ and $\mathrm{N} d r$, which are resolved using AutoCAD 3D models, are displayed in axonometry (Fig. 7a). The real sizes of the box sides, as well as the perspective images on them, are visible in the disassembly (Fig. 7b). Vanishing point $\mathrm{N} l y$ on the left perspective image and vanishing point Nry on the right, as a result of the same parallel ray, converge in a common point on the vertical edge of the box.

\section{Relief Perspective}

The relief perspective is a distortion of space which looks non-distortive when projected and viewed from a single viewpoint, and which uses the perspective method to resolve space with the aim of creating an illusion of greater spatial depth than is actually there (in the theatre, it is the depth of the stage space). Many examples of relief perspective application are known, both in stage design and in architecture. 

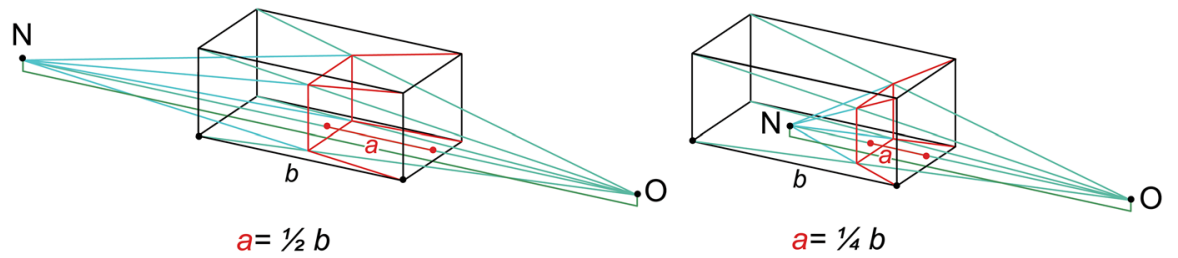

Fig. 8 Cuboid anamorphosis, constructed through the immediate method when its depth a is equal to: $\mathbf{a}$ half of depth $\mathbf{b}$ of the initial cuboid, axonometric display (image: author); $\mathbf{b}$ a quarter of depth $\mathbf{b}$ of the initial cuboid, axonometric display (image: author)

\section{Immediate Method}

The perspective collineation between imaginary 3D and the stage space is established by using the plane of a proscenium arch such as a collineation plane, so the scene backdrop (frontal) is taken as the perspective image of the most distant frontal wall of the original 3D space. The point of view is the centre of the perspective collineation of these two spaces and is taken in place of the "optimal viewer". Aiming to create as accurate a spatial illusion for the viewer as possible, several median perspectives are adopted, i.e. several points of view (Anagnosti 1988, p. 112).

The anamorphosis of the cuboid, from a certain viewpoint, is a truncated pyramid (Fig. 8). Examples (Fig. 8), which start with an imaginary object, in this case a cuboid, are solved through the immediate method. Point $\mathrm{N}$ is the vanishing point of all lines parallel to the visual ray $\mathrm{ON}$, so that the frontal side of the starting cuboid matches with the truncated pyramid base, without changing its size, while the back is made smaller. Depth $\boldsymbol{a}$ of the "perspective relief" determines the distance of vanishing point $\mathrm{N}$ from viewpoint $\mathrm{O}$. By increasing the depth of relief $\boldsymbol{a}$, the distance of vanishing point $\mathrm{N}$ from viewpoint $\mathrm{O}$ also grows. ${ }^{3}$

\section{Indirect Method}

Unlike the previous example, the indirect method of constructing a relief (Fig. 9) starts with the image of the imaginary $3 \mathrm{D}$ object. The image is also imaginary and is located in the $\pi$ plane. The indirect method encompasses, first, the solution of space by restituting the aforementioned image and using it to determine the location of the imaginary $3 \mathrm{D}$ object. Then, just as with the immediate method, a relief perspective is constructed based on the aforementioned object. Using the data that the initial perspective image displays a cuboid, point A2 of the imaginary cuboid is solved by bisecting the vision ray from viewpoint $\mathrm{O}$ through its imaginary initial perspective image A1 and the parallel with the main vision ray ON. The further process is the same for both the immediate and the indirect method.

The indirect method principle in stage design enables the transformation of different fields of view into a relief, and not just the perspective image in plane $\pi$

\footnotetext{
3 "If the relief depth is zero, we get the usual perspective." (Leopold 2014, p. 236).
} 


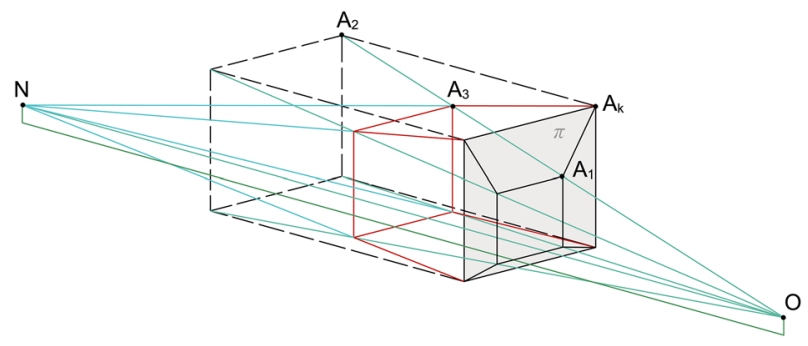

Fig. 9 Indirect method of constructing relief perspective, axonometric projection (image: author)

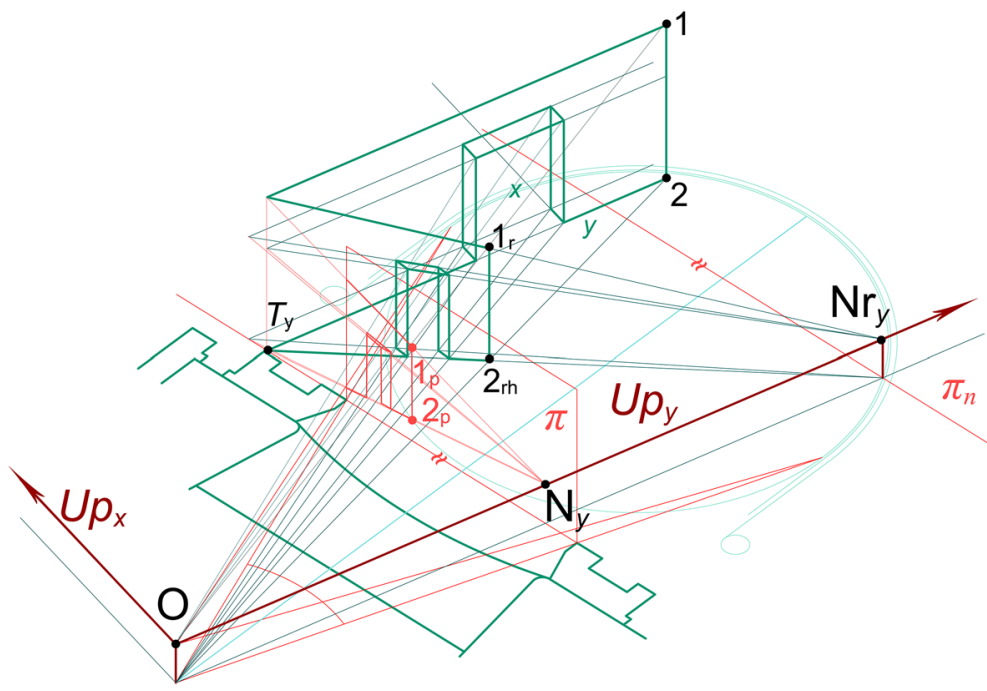

Fig. 10 Solving decor elements in a relief perspective using the indirect method, axonometric projection (image: author)

from a single viewpoint. Using this method, one gets an optimal stage design that contains projection relief decor elements from different viewpoints. In the following example (Fig. 10), an indirect method of a decor element whose perspective image in the angular perspective $\pi$ plane of a proscenium arch is shown. Using the aforementioned method of relief positioning, that is, plane $\pi_{n}$ where vanishing points $\mathrm{Nr}_{\mathrm{y}}$ and $\mathrm{Nr}_{\mathrm{x}}$ of the relief perspective is freely chosen within technical limitations. The initial object's Point 1 is obtained by restituting the perspective image $1_{\mathrm{p}}$ in the $\pi$ plane of the proscenium arch. The first thing to be resolved is the image restitution, followed by the perspective relief. Perspective image $2_{p}$ of Point 2 in a relief perspective isn't solved consistently. Due to practical reasons, it is lowered into the horizontal plane $2_{\mathrm{rh}}$, which is done for all points in the base plane. In order for the perspective of this relief to be convincing, it is necessary to mask such "lowered points" with moving decor. 


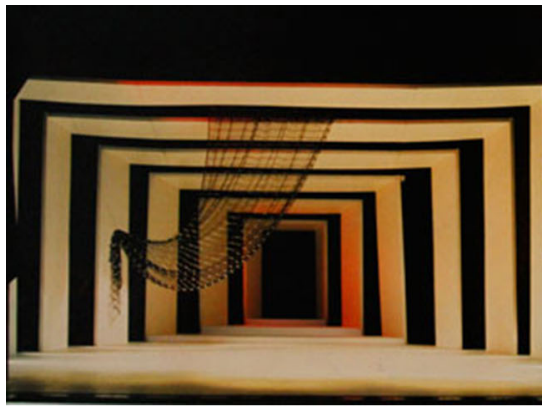

(a)

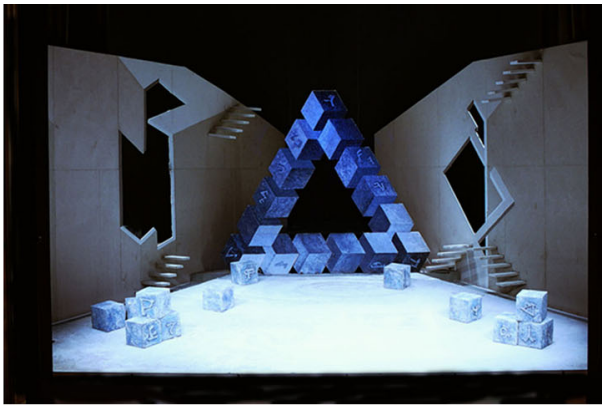

(b)

Fig. 11 Relief perspective: a Peer Gynt, scenography by Miodrag Tabački, 1988, Slovensko narodno gledalište, Ljubljana (source Miodrag Tabački); b Meeting point, scenography by Geroslav Zarić, National Theatre in Belgrade (source Geroslav Zarić)

The cogency, clarity and expressiveness of the spatial illusion obtained through relief perspective has always been supported by the pictorial perspective in which spatial relations are solved by using visual elements and rules for their composition. Scaling of the composition elements significantly contributes to the effect of the perspective. Depending on these elements, pictorial perspective ${ }^{4}$ can be achieved by using contrast (Fig. 11a) and using harmony (Fig. 11b).

\section{Cylindrical Perspective}

A theatre cyclorama is a curtain that is used as a backdrop, most frequently utilised to depict skies, open spaces or painted with neutral colours in order to hide backstage.

In practice, the ends of the cyclorama are often blocked with stage curtains and soffits, but by using different projection methods, its function can be expanded.

Presenting a 3D space on the internal surface of a rotational cylinder prevents the deformations that arise through projecting a 3D space on a plane. Motifs on the cyclorama can be solved with a perspective on the cylinder (Fig. 12), which, in contrast to empirical decorating, enables greater control during the realisation and painting of the cyclorama, as well as the visibility of a greater part of that surface.

When the position of a viewpoint is on the rotational vertical semi-cylinder's axis, the projections of the parallel horizontal lines are a curve (semi-ellipses) that passes through two vanishing points. Those vanishing points are intersection points of a view ray, parallel with some horizontal line, through a cylindrical surface. The horizon line is a semicircle, while the projections of the vertical lines, or straight parallel lines with the axis of a cylinder, stay parallel also in perspective, as the point of axial rotation of the aforementioned semi-cylinder is infinitely far.

\footnotetext{
4 "The pictorial perspective method involves any visual element such as devices whose physical properties can increase, reduce or neutralise the impression of spatial depth" (Marcikić 2002, p. 12).
} 


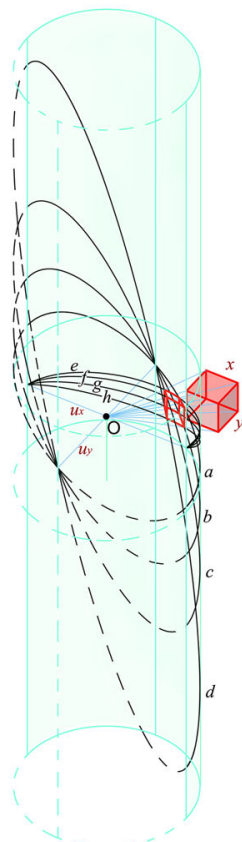

(a)

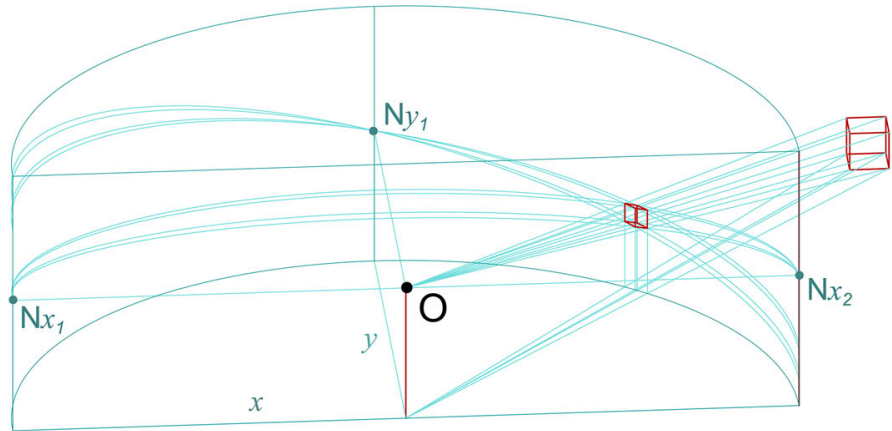

(b)

Fig. 12 Perspective of the cube and the carrier of its horizontal edges whose projections are ellipses, on a rotational cylinder's internal layer, axonometric display (image: author)

Even though the processes for creating perspective and an anamorphosis on a cylinder are the same, the effect they have is not the same, which is more important to the scene designer than to the audience. The audience can usually only see the perspective effect or an anamorphosis (unless it is part of the scenery), without having the possibility of being able to change its nature (i.e. they don't see the distortion). Perspective on the cylinder anamorphosis depends on the ratio of object sizes to the cylinder's diameter. When an object, which is projected on a cylindrical surface, is markedly smaller than the cylinder's diameter, the perspective projection is noticeable and the distortions are acceptable (Fig. 12b). However, when the object is noticeably large (for instance, in situations where the goal is to demonstrate the illusion of an elongated real space), the perspective projection is an anamorphosis (Fig. 13), and its distortions are significant.

In order to achieve such projects in practice, it is necessary to present the cylindrical perspective in the plane as an image on a rotational cylinder's unfolded layer.

The width $2 \mathrm{r} \pi, \pi=3.14159 \ldots$ of an unfolded layer of a vertical rotational cylinder, as well as the distance of the points of a cylindrical perspective, horizontally measured, are able to be graphically determined through the 


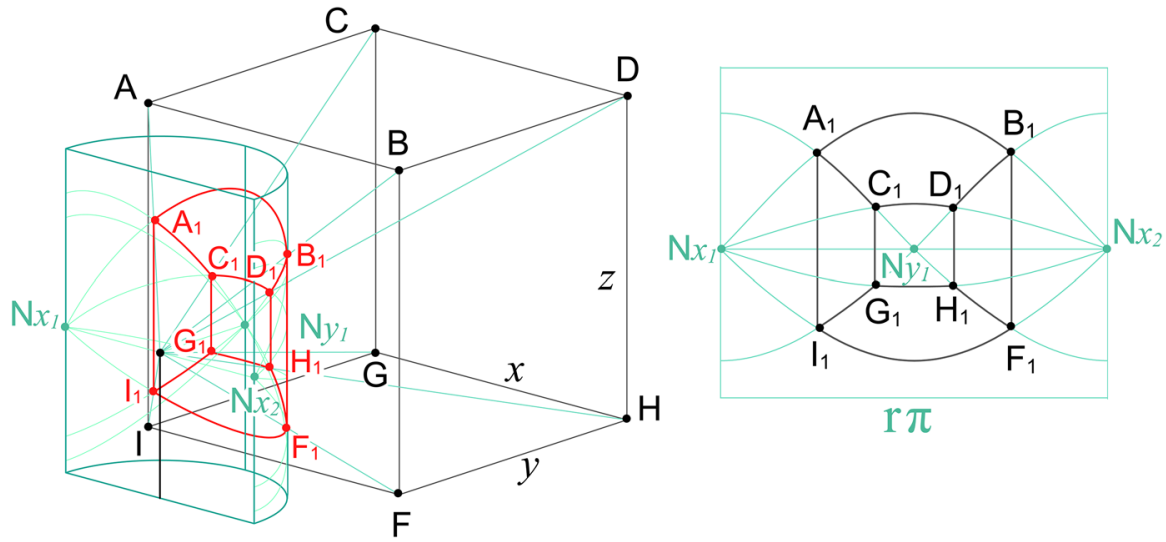

Fig. 13 Perspective of a cube with points of infinity on the internal layer of the rotational semi-cylinder, for the position of the viewpoint on the rotational axis; a axonometric projection (image: author); b display on a rotational semi-cylinder's unfolded layer (image: author)

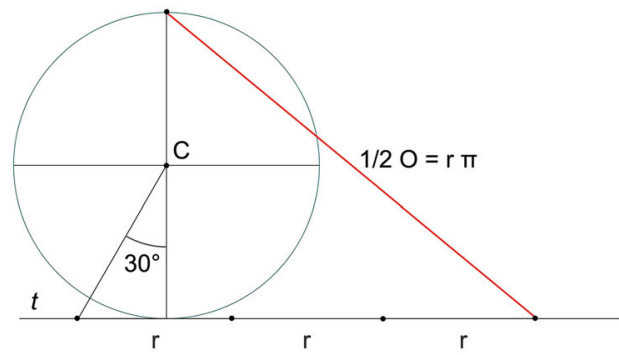

(a)

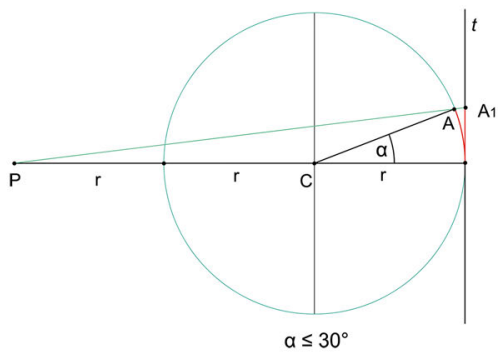

(b)

Fig. 14 Rectification of: a a circle according to Kohansky (A. Kohansky); b a circular arch on a tangent

rectification ${ }^{5}$ of a circle and its parts (Fig. 14). The height of the rectangle that is a grid of the cylinder layers is equal to the height of the cylinder.

The perspective on the half-cylinder is the image of an imaginary space projected on the layer of the half-cylinder.

If the viewpoint is located on a vertical half-cylinder axis, then the horizontal plane visual angle is $180^{\circ}$. If the viewpoint is outside the half-cylinder (which is most frequently the case with theatre plays), then the visual angle is less than $180^{\circ}$ (Fig. 15). The more the viewpoint is distant from the semi-cylinder, the more the visual angle is reduced.

In this case, the vertical line, as well as when the viewpoint is on the rotational cylinder axis, has a vanishing point as the projection of an infinitely distant point of a vertical parallel ray.

However, all lines, except the ones whose parallel rays $\left(U p_{3}, U p_{4}\right)$ are within the $\alpha$ angle, which enclose the tangential planes $\mathrm{O} t_{1}$ and $\mathrm{O} t_{2}$ on the cylinder through

\footnotetext{
5 Rectification (Lat. rectificatio) is the straightening of a curved line into a part of a line and the determination of the length of its parts.
} 


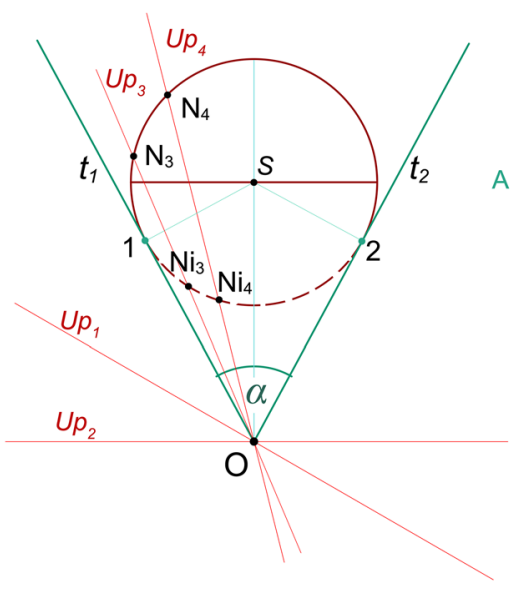

(a)

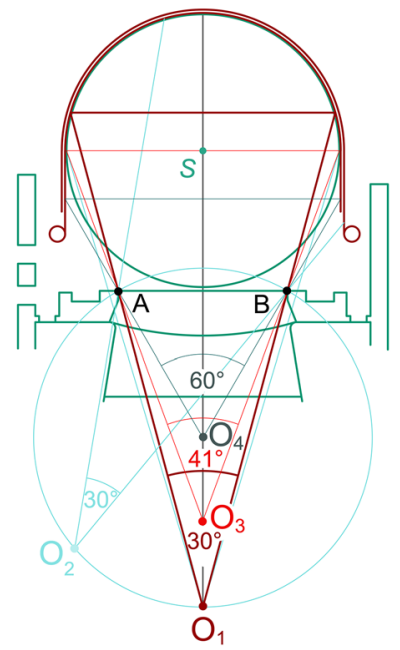

(b)

Fig. 15 Perspective on the internal layer of the cylinder when the viewpoint position is outside the surface: a angle $\alpha$ which encloses the tangential planes Ot 1 and Ot 2 on the cylinder, orthogonal projection (image: author); b ratio of the vision angle and the cylindrical surface, orthogonal projection (image: author)

viewpoint $\mathrm{O}$, have imaginary vanishing points (Fig. 15a). On the internal layer of the rotational cylinder, the perspective images of the lines that do not pass through the viewpoint are part of an ellipsis. Using Gellinek's method (Nikolić 2008, p. 38) the relationship between a determined visual angle and a cylindrical surface which encompasses that angle, on the main stage sample cyclorama at the National Theatre in Belgrade, is analysed (Fig. 15b). When the visual angle of $30^{\circ}$ from viewpoint $\mathrm{O}_{1}$ on the cyclorama surface symmetry axis, which is in the field of view, is smaller than the half-cylinder, the entire surface of the cyclorama is in a field of view under a $60^{\circ}$ angle.

In practice it is possible to solve the cylinder's surface by applying the indirect method where the imaginary objects' visual ray intersects with a cylindrical surface, but also with the immediate method where visual ray penetration through the initial perspective drawing, which can be located in the plane of the proscenium archvertical plane of the intersection, ${ }^{6}$ as well as in another plane characteristic of a certain field of vision (Fig. 15b). In this sense, the problem of the curved line perspective on the theatre cyclorama can be practically solved by using different perspective grids which will first be constructed on the unfolded layer of a rotational

\footnotetext{
6 Many authors have demonstrated the method of shifting the orthogonal surface onto a curved plane: Andrea Pozzo, author of illusionistic painting, The Apotheosis of St. Ignatius, on the nave vault of Sant'Ignazio in Rome, c. 1690-1694 demonstrates how to map a flat grid of squares onto a cylindrical vault (Andersen 2007, p. 394); Inácio Vieira in Tractado de Prospetiva (1716) demonstrates a sketch of the aforementioned model (Cabeleira and Coelho 2011, p. 326); also engraver Abraham Bosse 1653 in part of plate 2. (Andersen 2007, p. 464); John Kirby has shown an unfolded layer of a rotational halfcylinder grid (Andersen 2007, p. 558).
} 


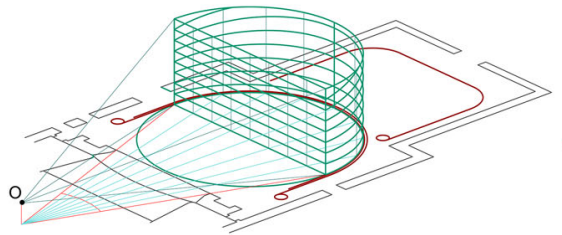

(a)

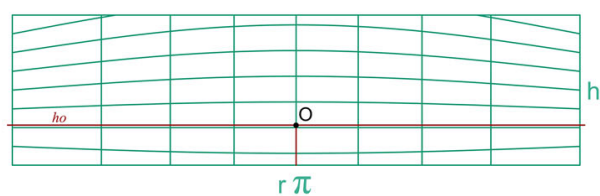

(b)

Fig. 16 Perspective projection of the orthogonal grid, which is in a cylinder's axis symmetrical plane perpendicular to the main visual ray: a axonometric projection of the model (image: author); b orthogonal grid on an unfolded layer (image: author)

semi-cylinder (Fig. 16), but also by creating ${ }^{7}$ and utilising different dedicated software and applications to simplify the creation of the perspective projections on the cylinder.

\section{Conclusion}

Seeing as how stage design directly impacts a theatre play's visual effects, by using 3D perspective anamorphosis in stage design one can achieve extraordinary $2 \mathrm{D}$ and 3D illusory spatial effects, especially the effects of multi-plane or cylindrical surface penetration, which contribute to the overall theatrical experience.

This study emphasises the importance of an inter-disciplinary approach in creating visual plays with interactions between various disciplines like geometry, art, architecture, optics, physiology and perception theory.

The constructive-geometrical analysis of carefully selected examples of 3D models of perspective anamorphosis gives the opportunity to establish a framework for a more efficient and more accurate projection and stage design creation. Such models can be applied in modern conditions on different levels of the realisation. The results of analysing models of this type of optical anamorphosis are unfolded images and grids that are applicable in projections of every individual element of stage decor, based on different fields of view, as well as stage design in its entirety. At The National Theatre in Belgrade it will significantly contribute to stage design.

The techniques of 3D mapping, reflected anamorphic images and augmented reality projections are used in contemporary stage design. In modern, minimalistic design those virtual images replace natural decor, whose scenography takes on a new function. All these listed geometrical procedures create content which can assume new meanings and forms through the process of digitalisation.

Acknowledgments As the authors, we wish to express our gratitude to the Ministry of Science and Technological Development of the Republic of Serbia, for supporting our research, which is part of Project No. TP 36008 entitled: Development and Application of Scientific Methods in Design and the Building of Highly Cost Effective Structural Systems with the Application of New Technologies.

\footnotetext{
7 An application of anamorphosis in stage design, which was discovered by Celestino Soddu in his research (Soddu 2010) into images generated by his own computer software, would be interesting.
} 


\section{References}

Anagnosti, P. 1988. Perspektiva. Beograd: Naučna knjiga.

Andersen, K. 2007. The Geometry of an Art: The History of the Mathematical Theory of Perspective from Alberti to Monge. Copenhagen: Springer.

Arnhajm, R. 1981. Umetnost $i$ vizuelno opažanje: Psihologija stvaralačkog gledanja. Beograd: Univerzitet umetnosti u Beogradu.

Cabeleira, J. and M. Coelho. 2011. Inacio Vieira: Optics and Perspective as Instruments Towards a Sensitive Space. Nexus Network Journal 13 (2): 315-335.

Cucakovic, Aleksandar and Marijana Paunovic (ex. Kalabic). 2011. Geometry of Optical Anamorphosis on the Example of Dutch Perspective Box. In Applied Geometry and Graphics 2011 Issue No 88, The Interdepartmental Collection of Proceedings (Crimea, Sudak, Ukraina, September 2011) ed. V.Ye. Mikhailenko, 205-210, Kyiv: Ukrainian Associaton of Applied Geometry.

Čučaković, A. and M. Paunović. 2015. Cylindrical Mirror Anamorphosis and Urban-Architectural Ambience. Nexus Network Journal 17 (2): 605-622.

Da Vinči, Leonardo. 1990. Traktat o slikarstvu. (Trattato della pittura) Eds. of original Carabba, Lanciano (1914) Beograd.

Kadijević, A. 2005. Estetika arhitekture Akademizma (XIX-XX vek), Beograd: Građevinska knjiga.

Leopold, C. 2014. Perspective Concepts - Exploring Seeing and Representation of Space. Journal for Geometry and Graphics 18 (2): 225-238.

Marcikić, I. 2002. Effects of the Constructions of Space in Visual Arts. Ph.D thesis, University of Arts in Belgrade.

Nikolić, D. 2008. Arhitektura scensko gledališnih prostora i tehnika scene. Beograd: BIRO ST- Scenska tehnika d.o.o.

Paunović, M. 2014. Optical Anamorphoses Constructed by the Means of Orthogonal Grids. In: 4th International Scientific Conference on Geometry and Graphics Mongeometrija 2014 Proceedings Volume 2 (Vlasina, June 2014) ed. Sonja Krasić, 257-268. Niš: Građevinsko- arhitektonski fakultet u Nišu i SUGIG.

Rossi, M. 2006. Natural Architecture and Constructed Forms: Structure and Surfaces from Idea to Drawing. Nexus Network Journal 8 (1): 112-122.

Soddu, C. 2010. Perspective, a Visionary Process: The Main Generative Road for Crossing Dimensions. Nexus Network Journal 12 (1): 33-46.

Verweij, A. 2010. Perspective in a box. Nexus Network Journal 12 (1): 47-62.

Aleksandar Čučaković born in 1958 in Belgrade, is a graduate Engineer of Architecture, holds a Master of Architectural and Urban Sciences, and a Ph.D. in Technical Sciences. Since 2005 he has held the position of Associate Professor of Descriptive Geometry at the Faculty of Civil Engineering, Department of Mathematics, Physics and Descriptive Geometry at the University of Belgrade, Serbia. His major research interests in the scientific field include: descriptive geometry, projective geometry, computational geometry, geometry of surfaces, geometric education, and applied geometry in architectural structures. $\mathrm{He}$ is a member of the International Society for Geometry and Graphics (ISGG), as well as a member of the Serbian Society for Geometry and Graphics (SUGIG).

Marijana Paunović born in 1982 in Belgrade, is a Ph.D. candidate at the Faculty of Architecture, University of Belgrade. She has taught at the Faculty of Applied Arts, University of Arts in Belgrade, since 2007. She graduated from the Faculty of Applied Arts in 2007, and was awarded a scholarship by the Ministry of Science and Technological Development of the Republic of Serbia (2009-2012). She is a member of The Association of Applied Arts Artists and Designers of Serbia (2007-), The Serbian Society for Geometry and Graphics (2008-), as well as being a member of the International Society for Geometry and Graphics (2014-). Her research interest is in Applied Geometry. The topic of her doctoral dissertation: "Geometrical 3D models and methods of construction of anamorphoses with applications in visual arts" has its origin in the technical-technological sciences, scientific field: architecture and urbanism. 